\title{
Unravelling pH Changes in Electrochemical Desalination with Capacitive Deionization
}

\author{
Antony C. Arulrajan, Jouke E. Dykstra,* Albert van der Wal, and Slawomir Porada* \\ Cite This: Environ. Sci. Technol. 2021, 55, 14165-14172 \\ Read Online
}

ACCESS | Lلlll Metrics \& More | 回 Article Recommendations | st Supporting Information

ABSTRACT: Membrane capacitive deionization (MCDI) is a water desalination technology employing porous electrodes and ion-exchange membranes. The electrodes are cyclically charged to adsorb ions and discharged to desorb ions. During MCDI operation, a difference in $\mathrm{pH}$ between feed and effluent water is observed, changing over time, which can cause the precipitation of hardness ions and consequently affect the long-term stability of electrodes and membranes. These changes can be attributed to different phenomena, which can be divided into two distinct categories: Faradaic and non-Faradaic. In the present work, we show that during long-term operation, as the electrodes age over time, the magnitude and direction of $\mathrm{pH}$ changes shift. We studied these changes for two different feed water solutions: a $\mathrm{NaCl}$

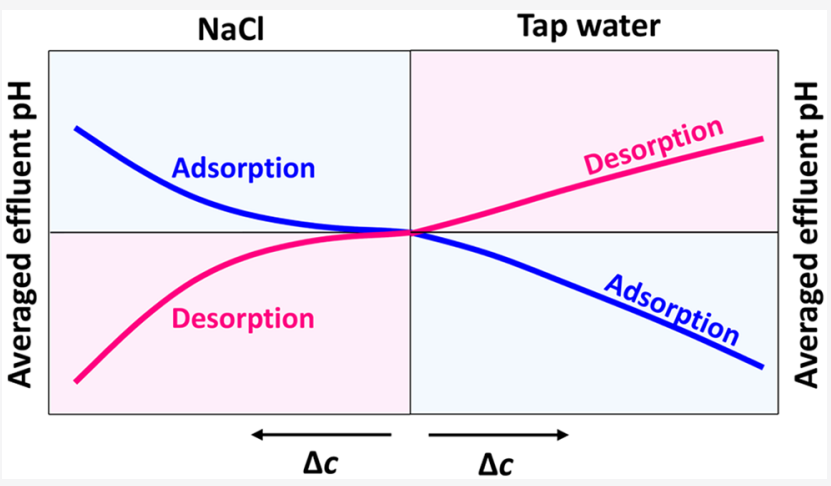
solution and a tap water solution. Whereas we observe a $\mathrm{pH}$ decrease during the regeneration with a $\mathrm{NaCl}$ solution, we observe an increase during regeneration with tap water, potentially resulting in the precipitation of hardness ions. We compare our experimental findings with theory and conclude that with aged electrodes, non-Faradaic processes are the prominent cause of $\mathrm{pH}$ changes. Furthermore, we find that for desalination with tap water, the adsorption and desorption of $\mathrm{HCO}_{3}{ }^{-}$and $\mathrm{CO}_{3}{ }^{2-}$ ions affect the $\mathrm{pH}$ changes.

KEYWORDS: membrane capacitive deionization, $p H$ changes, Faradaic reactions, non-Faradaic processes, amphoteric ions

\section{INTRODUCTION}

Increasing demand for surface water and groundwater has resulted in water stress and scarcity in many countries. ${ }^{1}$ To overcome water scarcity, technologies can be employed to produce potable water from brackish or saline sources. ${ }^{2}$ Capacitive deionization (CDI) is one such technology for water desalination employing porous electrodes, which are cyclically charged and discharged. In conventional CDI, during the charging step, ions are adsorbed in electrical double layers (EDLs) in the micropores of the porous electrodes, and feed water is desalinated. During discharge, ions are desorbed, resulting in a concentrated effluent stream.,

Although CDI is a promising technology for brackish water desalination, stable long-term operation remains a challenge. ${ }^{3,5}$ In addition to capacitive ion storage in EDLs, undesirable Faradaic processes also occur. ${ }^{6,7}$ These Faradaic processes are considered to be the main reason for a decrease in desalination performance over time. Furthermore, these processes can cause $\mathrm{pH}$ changes during desalination, ${ }^{8-10}$ which can result in the precipitation of salt when hardness ions $\left(\mathrm{Mg}^{2+}, \mathrm{Ca}^{2+}\right.$, and $\mathrm{Fe}^{2+} /$ $\left.\mathrm{Fe}^{3+}\right)$ and carbonate ions $\left(\mathrm{HCO}_{3}{ }^{-}\right.$and $\left.\mathrm{CO}_{3}{ }^{2-}\right)$ are present in solution and consequently affect the desalination performance and long-term stability of the CDI cell. ${ }^{8-10}$
Several mechanisms cause $\mathrm{pH}$ changes in CDI, which can be divided into two categories: Faradaic reactions and nonFaradaic processes. Non-Faradaic processes, such as differences in ionic mobilities, affect individual ion adsorption rates, for example of $\mathrm{H}^{+}$and $\mathrm{OH}^{-}$, and thereby the local $\mathrm{pH}$. Other processes that must be considered are acid-base reactions between ionic species, and the protonation or deprotonation of chemical surface groups present on the electrode material, which can also result in $\mathrm{pH}$ changes during CDI operation. ${ }^{11}$ Faradaic reactions that can occur, either at the anode or at the cathode, have also been studied. While at the anode, reactions such as carbon, chloride, and water oxidation are mostly considered, at the cathode, the reduction of dissolved oxygen and water is relevant. ${ }^{6,7,12,13}$ Among these reactions, carbon oxidation and dissolved oxygen reduction have been shown to significantly destabilize the desalination performance. At the anode, carbon oxidation results in the formation of oxygen-

Received: July 9, 2021

Published: September 29, 2021

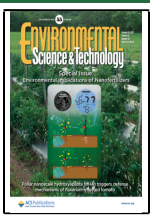


MCDI

(a)

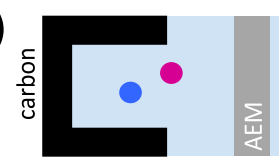
spacer
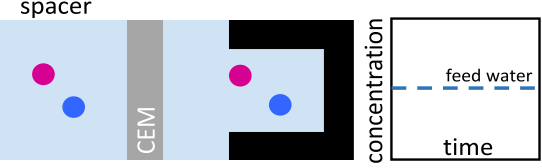

bharging

(b)
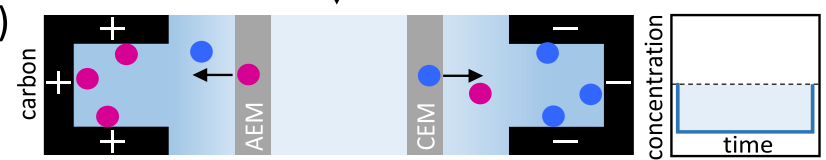

(c)

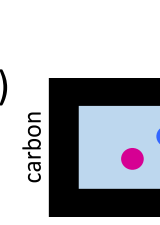

\section{$\downarrow$ discharging}

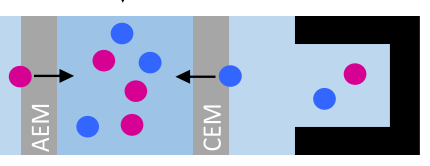

anions

cations

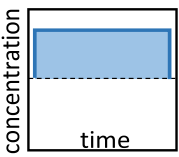

\section{i-MCDI}

(d)

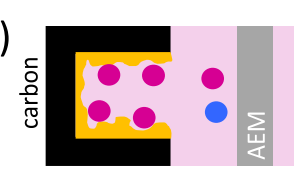

spacer

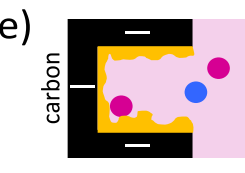

$\downarrow$ charging
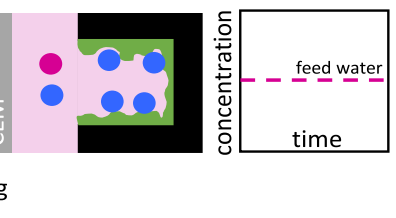

time

(f)
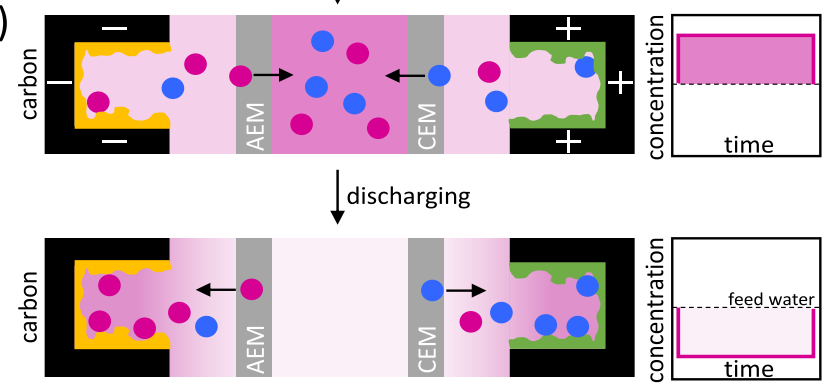

discharging
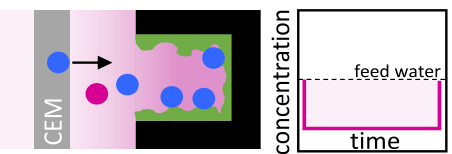

cation-exchange polymer

Figure 1. MCDI $(a-c)$ and inverted MCDI (i-MCDI) (d-f) for cyclic water desalination. In MCDI, water is desalinated during charging (b), and the electrodes are regenerated during discharge (c). In i-MCDI, the electrodes are modified with ion-exchange polymers which are located in the carbon pores, resulting in high counterion concentrations in the electrodes in the uncharged state (d). During charging, these ions are expelled from the electrode compartments, and a concentrated salt solution (concentrate) is produced (e). During discharge, water is desalinated (f).

containing chemical groups. The direct consequence of these oxygenated surface groups is the occurrence of "inversion peaks" during operation which lowers the desalination efficiency by enhanced coion expulsion from the electrodes. ${ }^{14}$ At the cathode, oxygen reduction has experimentally been confirmed by measuring the dissolved oxygen and hydrogen peroxide concentration changes in the effluent water during CDI operation. ${ }^{15}$ Other Faradaic processes that can occur during operation are chloride oxidation (formation of $\mathrm{Cl}_{2}$ gas) at the anode and water reduction (formation of $\mathrm{H}_{2}$ gas) at the cathode. Formed $\mathrm{Cl}_{2}$ gas can immediately dissociate in water to form $\mathrm{HOCl}$, resulting in a decreased effluent $\mathrm{pH} .{ }^{6}$ Faradaic reactions related to carbon oxidation occur mainly on pristine electrodes, which are electrodes that have only been used for a limited number of cycles before the study was conducted. ${ }^{5}$

In order to mitigate negative effects of Faradaic processes in CDI, three main strategies have been proposed. First, different operational modes have been investigated to limit the cell voltage, to optimize the operational voltage window, ${ }^{16-18}$ or to invert the cell voltage applied during charging and discharging steps. ${ }^{19,20}$ Second, alternative CDI cell designs are considered, either by applying different flow patterns (i.e., flow by/flow through) ${ }^{17,18}$ or by placing ion-exchange membranes (IEMs) between the flow channels and the porous electrodes, a cell design we refer to as membrane capacitive deionization (MCDI) ${ }^{21-23}$ Third, electrode modifications, such as titania deposition on carbon to prevent carbon oxidation, have been proposed. $^{24,25}$

One of the most effective strategies to keep a high desalination performance is the inclusion of IEMs in the CDI cell, a cell design we refer to as MCDI. These IEMs are placed in front of the electrodes and contribute to maintaining the desalination performance in two ways: the membranes effectively slow down the transport of dissolved oxygen to the electrodes and consequently limit the rate of carbon oxidation and the related $\mathrm{pH}$ changes. ${ }^{26,27}$ However, during long-term operation, dissolved oxygen will eventually oxidize the electrically positively polarized electrode (anode), and oxygen-containing surface groups will form. ${ }^{22,28}$ Whereas these groups would have negatively affected the desalination performance in CDI (without membranes) due to enhanced coion expulsion during desalination, in MCDI, the desalination performance does not decline because IEMs prevent coions from leaving the electrode region. ${ }^{22,28}$ Furthermore, Faradaic reactions during $\mathrm{MCDI}$ operation were also confirmed in our previous work by microscopic physics-based modeling of $\mathrm{pH}$ changes. ${ }^{11}$ This study predicted only minor $\mathrm{pH}$ changes during desalination in MCDI when non-Faradaic processes, including the effect of different mobilities of various ions on transport rates, combined with acid-base reactions and the presence of chemical surface groups in the micropores are taken into account. In order to match theoretical predictions of $\mathrm{pH}$ changes with experimental data, this study concluded that Faradaic reactions in the micropores must be considered. ${ }^{11}$

MCDI has successfully been applied on industrial scale, and systems have been running for many consecutive cycles. ${ }^{29}$ In these systems, $\mathrm{pH}$ changes are still observed, and although these changes do not directly affect the salt adsorption performance, they can still be problematic.

Experimentally and theoretically, many studies have reported a $\mathrm{pH}$ decrease during desorption if the feed water only contains sodium chloride. However, the present work shows that with real brackish water (tap water), which contains a mixture of different ions, a $\mathrm{pH}$ increase is observed during desorption. This $\mathrm{pH}$ increase during desorption is problematic, especially when we operate at high water recoveries, resulting in high salt concentrations in the flow channel during desorption. These conditions, with high salt concentrations combined with high $\mathrm{pH}$ values, can lead to the precipitation of salts such as calcium carbonate (scaling) on membranes or other components of the CDI cell. Furthermore, if the aim is to remove amphoteric ions, which are ions that can protonate and deprotonate based on solution $\mathrm{pH}$, such as phosphate, ammonium, carbonate and boron, the local $\mathrm{pH}$ affects the charge of the ion and thus the removal performance.

To improve our understanding of these $\mathrm{pH}$ fluctuations, we conducted experiments with aged electrodes. These aged electrodes have been used in MCDI for more than 2000 
desalination cycles and are therefore (partly) oxidized. Furthermore, we conduct experiments both with a $\mathrm{NaCl}$ solution and with tap water, and we perform experiments with different water recoveries to be close to practical desalination conditions. We study these fluctuations in conventional MCDI operation and in i-MCDI operation. In i-MCDI, electrodes are chemically modified: we synthesized an electrode with positively charged chemical groups and an electrode with negatively charged chemical groups. A cation-exchange membrane (CEM) was placed in front of the electrode modified with negatively charged chemical groups and an anion-exchange membrane (AEM) was placed in front of the electrode modified with positively charged chemical groups (Figure 1). Fritz et al. (2019) demonstrated that this configuration can be successfully employed for water desalination, that water is desalinated during discharge (adsorption), and that a concentrated effluent stream (desorption) is produced during the charging step. ${ }^{30}$

This study reports $\mathrm{pH}$ fluctuations with aged electrodes in MCDI and i-MCDI operation at different water recoveries. Furthermore, we compare our experimental findings of the $\mathrm{NaCl}$ experiments with theory that only includes non-Faradaic processes, and we find that the theory describes the trends of the experimental data well.

\section{MATERIALS AND METHODS}

Desalination experiments were conducted using an MCDI and an i-MCDI stack. The MCDI stack consisted of two cells, each with two activated carbon electrodes (PACMM 203, $\delta_{\mathrm{e}} \sim 250$ $\mu \mathrm{m}$, Material Methods, Irvine, CA, USA), two IEMs, and a nylon spacer for an evenly distributed water flow. A CEM (Neosepta CMX, ASTOM Corporation, Tokyo, Japan) was placed in front of one electrode, an AEM (Neosepta AMX, ASTOM Corporation, Tokyo, Japan) was placed in front of the other, and a nylon spacer was placed between the membranes. The i-MCDI stack consisted of two cells with chemically modified electrodes, which were activated carbon electrodes modified with ion-exchange polymers. Anionexchange polymer-modified electrodes (AEPEs) were prepared by immersing activated carbon electrodes in an ionomer solution [FAS solution, $24 \mathrm{wt} \%$ of the polymer dissolved in $\mathrm{N}$ methyl-2-pyrrolidone (NMP); Fumatech, Bietigheim-Bissingen, Germany] that was diluted six times using NMP. Immersed electrodes were then placed inside a vacuum chamber for $30 \mathrm{~min}$ and then dried for $24 \mathrm{~h}$ at $100{ }^{\circ} \mathrm{C}$. Similarly, the cation-exchange polymer-modified electrodes (CEPEs) were prepared by immersing the activated carbon electrode in a six-time-diluted (using NMP) ionomer solution (FKS solution, 16 wt \% of the polymer dissolved in NMP; Fumatech, Bietigheim-Bissingen, Germany). After modification, the electrodes were washed with ultrapure water before placement in the i-MCDI stack. The i-MCDI stack consisted of two cells, each with an AEPE and a CEPE. In front of each CEPE electrode, a CEM was placed, and in front of each AEPE electrode, an AEM was placed, and a nylon spacer was placed between the CEM and AEM. Graphite sheets were used as current collectors to electrically connect the porous carbon electrodes with the external electrical circuit, which connects the stack to a potentiostat (Iviumstat, Ivium Technologies, The Netherlands).

All desalination experiments were conducted using aged electrodes and $\mathrm{NaCl}$ solutions prepared using ultrapure water (resistivity of $18.2 \Omega \mathrm{cm}$ at $25{ }^{\circ} \mathrm{C}$ ) or tap water. The electrodes were aged by charging and discharging the MCDI stack for more than 2000 and the i-MCDI stack for more than 3000 desalination cycles using constant current operational mode with a fixed current density $\left(11.1 \mathrm{~A} / \mathrm{m}^{2}\right)$, and a $5 \mathrm{mM} \mathrm{NaCl}$ solution, which was constantly purged with compressed air, was pumped through the MCDI or i-MCDI stack at a 12.5 $\mathrm{mL} / \mathrm{min}$ flow rate (effluent $\mathrm{pH}$ changes during the aging process of an MCDI stack are shown in Figure S1). After the aging process, to compare experimental data with theoretical calculations, desalination experiments were conducted with 5 and $20 \mathrm{mM} \mathrm{NaCl}$ solutions which were purged with $\mathrm{N}_{2}$. Thereafter, further desalination experiments were conducted, either with a $5 \mathrm{mM} \mathrm{NaCl}$ solution purged with air or with tap water (not purged with air, neither with $\mathrm{N}_{2}$ ), for $80-100$ desalination cycles. All desalination experiments were conducted in constant current operational mode with the same current density and flow rate used during the aging process. Desalination experiments were conducted for different values of water recovery. To increase water recovery, the flow rate during desorption was reduced. During desalination experiments with $\mathrm{NaCl}$ solution, the feed water was pumped from a $50 \mathrm{~L}$ tank which was purged with compressed air to the MCDI or i-MCDI stack and the effluent water was recycled to the same tank. In the tap water experiments, the feed water was pumped from a $20 \mathrm{~L}$ tank to the MCDI or i-MCDI stacks and the effluent water was not recycled. The tap water feed tank was constantly refilled to maintain the water level. During desalination experiments, the feed water $\mathrm{pH}$ was continuously measured using a $\mathrm{pH}$ sensor connected to the stack inlet. Similarly, the effluent $\mathrm{pH}$ and conductivity were continuously measured.

For the desalination experiments conducted with a $\mathrm{NaCl}$ solution, the salt concentration was calculated from the measured conductivity using a calibration curve. For the tap water experiments, in addition to the online conductivity and $\mathrm{pH}$ measurements, the effluent water during adsorption and desorption (from the last three cycles of each experiment) was collected separately and the $\mathrm{pH}$ was immediately measured after sampling. Also, the concentrations of cations $\left(\mathrm{Na}^{+}, \mathrm{K}^{+}\right.$, $\mathrm{Ca}^{2+}$, and $\left.\mathrm{Mg}^{2+}\right)$ and anions $\left(\mathrm{Cl}^{-}, \mathrm{NO}_{3}{ }^{-}, \mathrm{PO}_{4}{ }^{3-}\right.$, and $\left.\mathrm{SO}_{4}{ }^{2-}\right)$ present in the samples were analyzed using inductively coupled plasma-optical emission spectroscopy (ICP-OES, Optima 5300 DV, PerkinElmer) and ion chromatography (IC, Dionex Aquion, Thermo Scientific) which are shown in Table S1 in the Supporting Information. The concentration of dissolved inorganic carbon (DIC), i.e., the total concentration of the ionic species $\mathrm{H}_{2} \mathrm{CO}_{3}, \mathrm{HCO}_{3}{ }^{-}$, and $\mathrm{CO}_{3}{ }^{2-}$, and the effluent $\mathrm{pH}$ (during adsorption and desorption) were calculated using Visual MINTEQ 3.1 software, as discussed in the next section.

pH and Ionic Speciation Calculations Using Visual MINTEQ. Visual MINTEQ 3.1 is a software tool that uses a chemical equilibrium model to calculate, in water, the ionic speciation, the solubility, and several parameters related to the water chemistry, including $\mathrm{pH}$ and DIC, which are calculated based on charge and mass balances of the different (ionic) species in solution. In our study, we used MINTEQ to calculate the $\mathrm{pH}$ and DIC of water samples by including the experimentally determined concentrations of all other ions from ICP-OES and IC analysis (Supporting Information, Table S1). Furthermore, we specify the partial $\mathrm{CO}_{2}$ gas pressure in air, which is in equilibrium with the aqueous phase. With these inputs, the $\mathrm{pH}$, the total concentration of DIC, and the speciation thereof (concentrations of $\mathrm{H}_{2} \mathrm{CO}_{3}, \mathrm{HCO}_{3}{ }^{-}$, and 


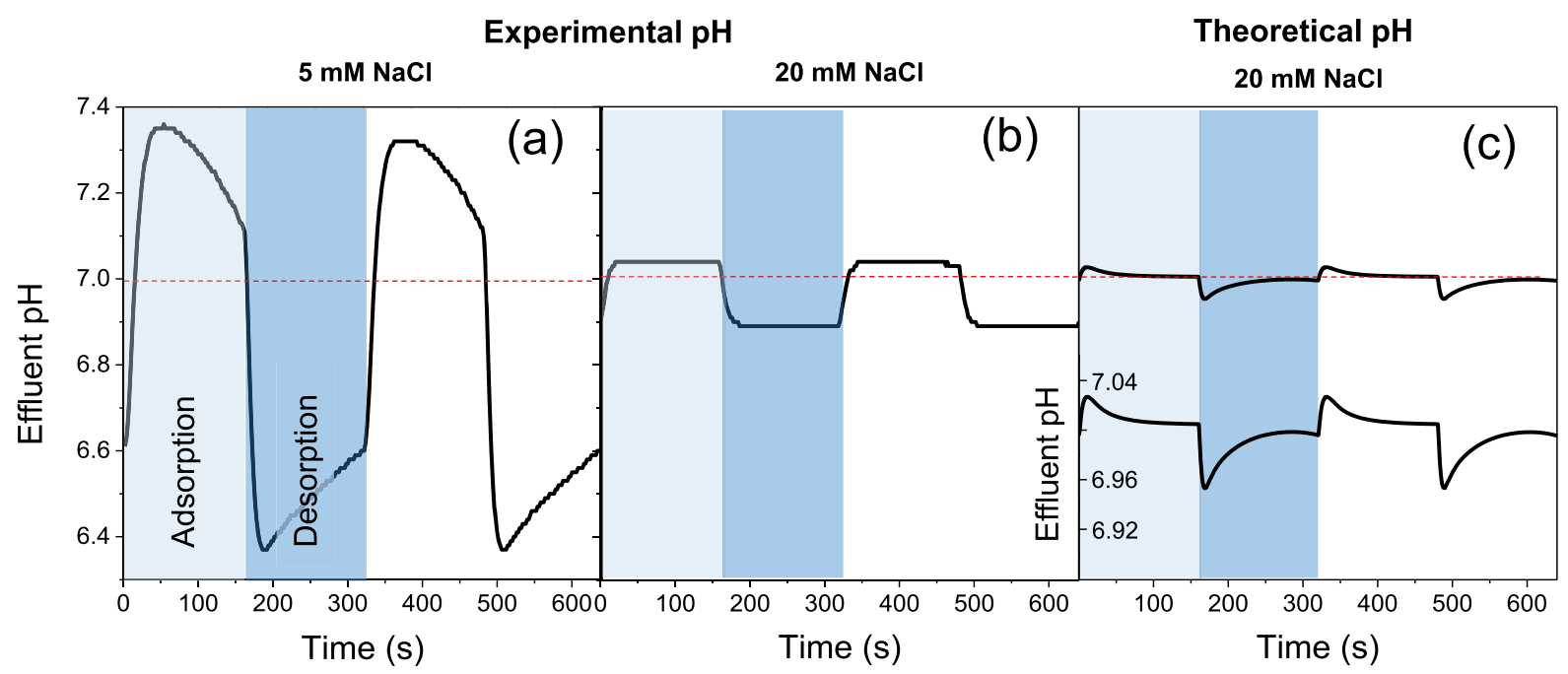

Figure 2. Experimentally observed effluent $\mathrm{pH}(\mathrm{a}, \mathrm{b})$ and theoretically calculated effluent $\mathrm{pH}$ (c) for $\mathrm{MCDI}$ in a $\mathrm{N}_{2}$-purged $\mathrm{NaCl}$ solution. The inset in $\mathrm{c}$ shows the theoretically calculated zoomed effluent $\mathrm{pH}$ change.

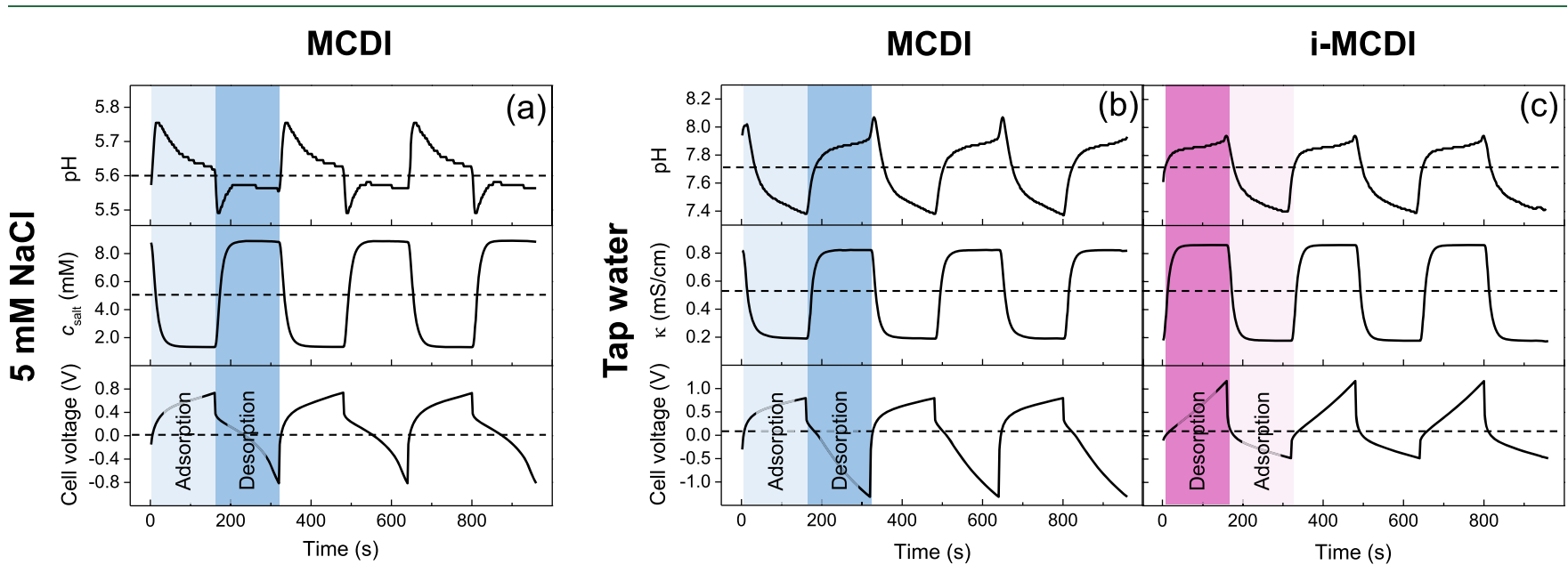

Figure 3. Cell voltage, effluent concentration (or conductivity in the case of tap water), and effluent $\mathrm{pH}$ changes of $\mathrm{MCDI}$ experiments with a $\mathrm{NaCl}$ solution (a) and with tap water (b) and i-MCDI experiments with tap water (c) after reaching dynamic steady state.

$\mathrm{CO}_{3}{ }^{2-}$ ) were calculated by MINTEQ for tap water and for effluent water during adsorption and desorption.

\section{RESULTS AND DISCUSSION}

Comparing Data and Theory: Desalinating a $\mathrm{NaCl}$ Solution. Desalination experiments were conducted using an MCDI stack with aged electrodes and a $\mathrm{N}_{2}$-purged $\mathrm{NaCl}$ solution for 100 desalination cycles. With aged electrodes, the average concentration reduction during a desalination step, $\Delta c$, and charge efficiency were stable for all 100 cycles (see Supporting Information, Figure S2). During the adsorption step, the effluent $\mathrm{pH}$ is higher than the feed $\mathrm{pH}$, whereas during desorption, the effluent $\mathrm{pH}$ is lower than the feed $\mathrm{pH}$, see Figure 2. We compare experimentally observed and theoretically predicted effluent $\mathrm{pH}$ changes by employing the theoretical framework as described in a previous work, ${ }^{11}$ which considers the effect of non-Faradaic phenomena, including the effect of different diffusion coefficients of the ions present in solution, and the presence of chemical surface groups. ${ }^{11}$ The theoretical $\mathrm{pH}$ changes are calculated for a feed solution with a $\mathrm{NaCl}$ concentration of $20 \mathrm{mM}$, whereas the experiments were performed with feed concentrations of 5 and $20 \mathrm{mM}$.
Interestingly, we observe, considering the trend, a good description of the effluent $\mathrm{pH}$ changes by theory, i.e., we observe a $\mathrm{pH}$ increase during adsorption and a $\mathrm{pH}$ decrease during desorption. The dynamics of experimentally observed $\mathrm{pH}$ changes with a $5 \mathrm{mM} \mathrm{NaCl}$ solution, both for a solution purged with $\mathrm{N}_{2}$ (Figure 2a) and with air (Figure 3a), is similar to the theoretically calculated $\mathrm{pH}$ changes for a $20 \mathrm{mM} \mathrm{NaCl}$ solution, but the magnitude of the experimentally observed $\mathrm{pH}$ changes is larger than that predicted by theory. For the $20 \mathrm{mM}$ $\mathrm{NaCl}$ feed solution, the magnitude of experimentally observed $\mathrm{pH}$ changes is similar to that of the theoretical predictions for the adsorption step, whereas for the desorption step, the magnitude is slightly larger than that predicted by theory. However, the dynamics is not similar to the predictions, which could possibly be explained by the limited sensitivity of the $\mathrm{pH}$ sensor $(<0.1 \mathrm{pH}$ unit). Clearly, the theory, which only includes non-Faradaic phenomena, such as the effect of different diffusion coefficients of the ionic species present in solution, describes the data well compared to our previous study. ${ }^{11}$ In our previous study, we compared theory with experiments conducted with pristine electrodes, and we concluded that Faradaic phenomena must be considered to explain the 
a)

MCDI

b)

i-MCDI

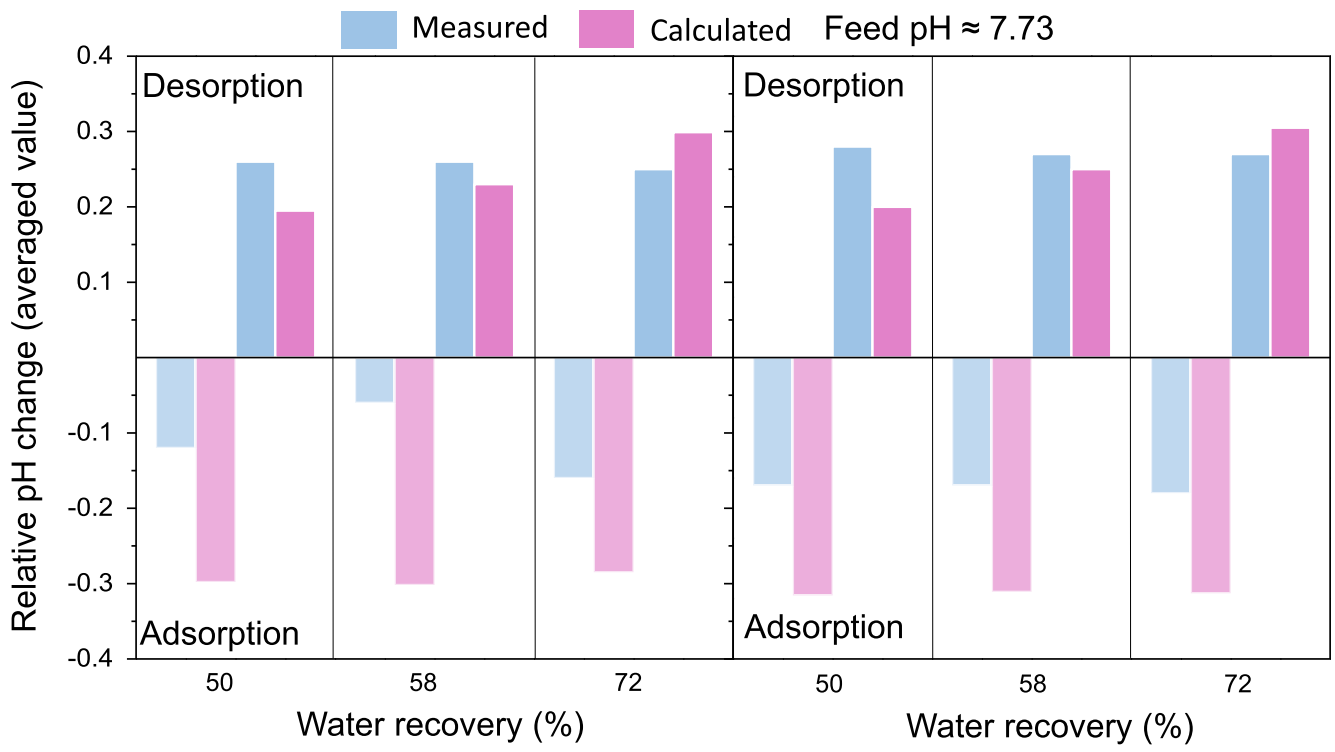

Figure 4. Comparison between experimentally measured and theoretically calculated effluent $\mathrm{pH}$ changes in MCDI and i-MCDI during tap water desalination.
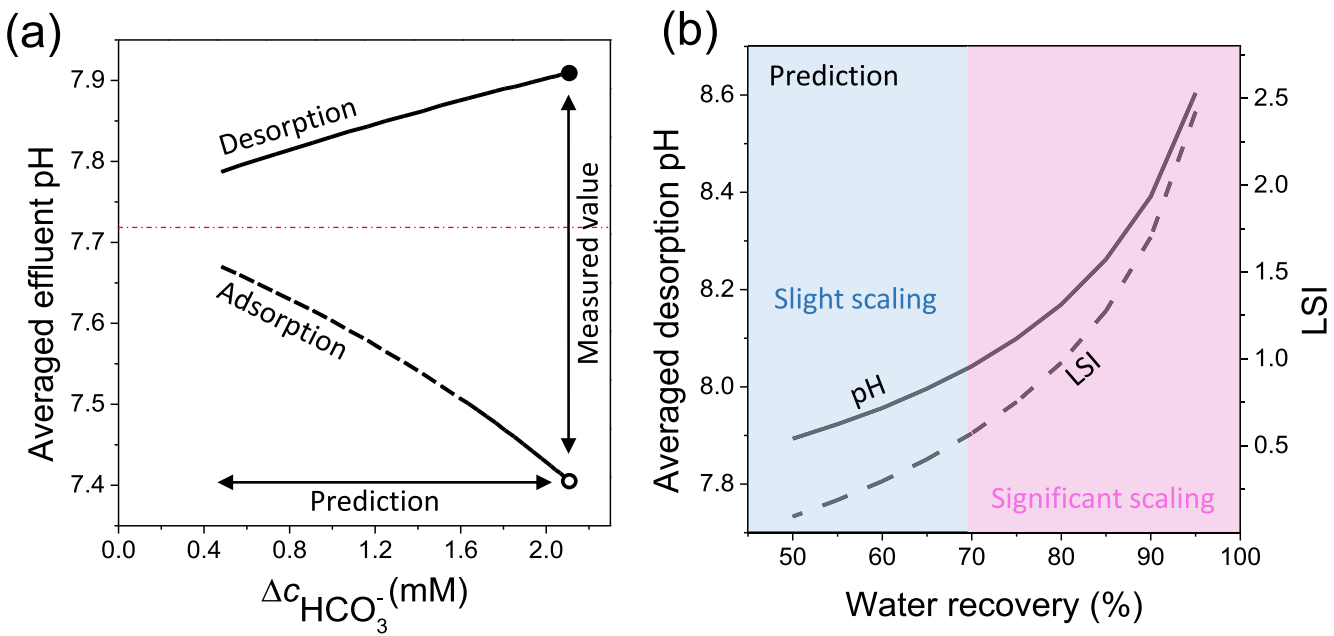

Figure 5. (a) Effluent $\mathrm{pH}$ prediction as a function of bicarbonate ion removal, $\Delta c_{\mathrm{HCO}_{3}}$. (b) Prediction of effluent $\mathrm{pH}$ during desorption for different water recoveries. (c) Prediction of Langelier saturation index (LSI) as a function of water recovery.

experimental data. In the present work, however, we used aged electrodes, and the agreement of theory with data indicates that with aged electrodes, non-Faradaic phenomena are the prominent cause of $\mathrm{pH}$ changes.

Furthermore, we studied $\mathrm{pH}$ changes with an air-purged $\mathrm{NaCl}$-containing solution and with tap water (see Table S1 for the exact composition of the tap water). The $\mathrm{pH}$ of the $\mathrm{NaCl}$ solution purged with air reduces to 5.6 as $\mathrm{CO}_{2}$ from air dissolves in water, resulting in the formation of carbonic acid $\left(\mathrm{H}_{2} \mathrm{CO}_{3}\right)$ which then dissociates into protons, bicarbonate, and carbonate ions. The $\mathrm{pH}$ of tap water is 7.72 due to the presence of carbonate and bicarbonate ions in the solution. The sum of the concentrations of hardness ions, i.e., calcium and magnesium, and of bicarbonate/carbonate ions present in the tap water studied in this work is in the range of moderately hard water. The desalination experiments were done for 80100 cycles to reach dynamic steady state, which means that the cell voltage, salt adsorption, and effluent $\mathrm{pH}$ of a particular cycle are the same as of the previous cycle (see Figure S3 for averaged $\mathrm{pH}$ and peak cell voltage for $80-100$ cycles). These results are shown in Figure 3a,b. Interestingly, for the MCDI experiments conducted with tap water, the $\mathrm{pH}$ changes are reversed compared to the case of $\mathrm{NaCl}$, i.e., the $\mathrm{pH}$ value decreases during adsorption and increases during desorption (Figure $3 \mathrm{~b}$ ). As the observed $\mathrm{pH}$ increase during desorption with tap water can result in scaling, strategies have to be developed and explored to invert these changes. To that end, tap water desalination experiments were conducted with an iMCDI stack. Figure $3 \mathrm{c}$ shows that the effluent $\mathrm{pH}$ changes observed in i-MCDI are, for tap water desalination, similar to those in MCDI: the effluent $\mathrm{pH}$ decreased during adsorption and increased during desorption. This finding suggests that the $\mathrm{pH}$ changes in tap water are independent of cell operation during adsorption and desorption.

In order to get more insight into $\mathrm{pH}$ changes with tap water, after steady state is reached in tap water desalination 


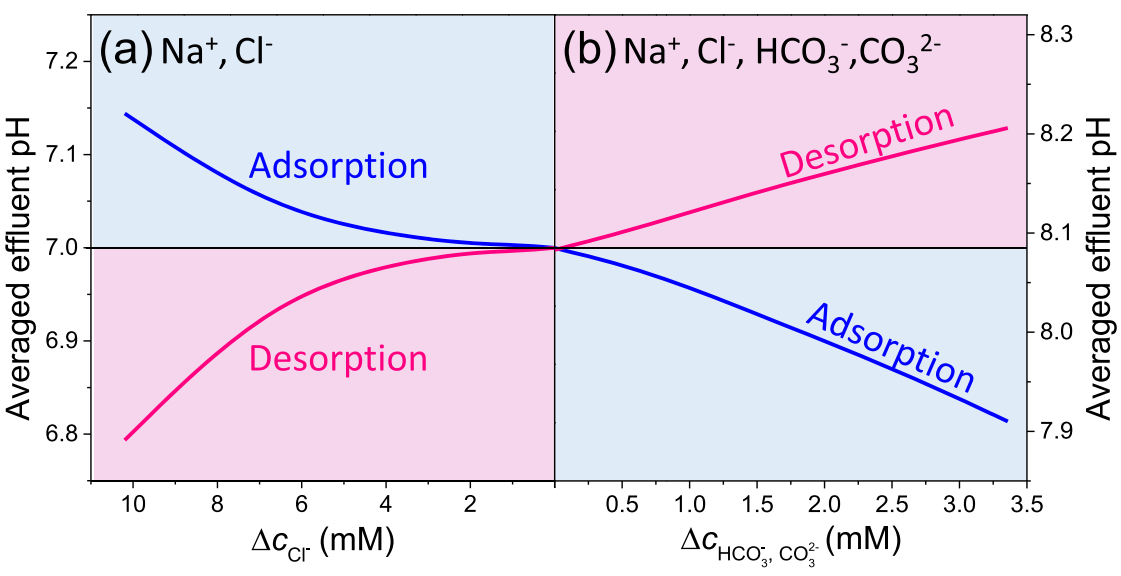

Figure 6. (a) Effluent $\mathrm{pH}$ calculated for different values of the concentration reduction of $\mathrm{NaCl}$ (i.e., $\left.\Delta c_{\mathrm{Cl}^{-}}\right)$and (b) prediction of the effluent $\mathrm{pH}$ at fixed concentration reduction $(\Delta c=3.45 \mathrm{mM})$ with different concentration reductions of carbonate species $\left(\Delta \mathrm{CHCO}_{3}{ }^{-}, \mathrm{CO}_{3}{ }^{2-}\right)$ over Cl$^{-}$.

experiments, the effluent water during adsorption and desorption is collected (after 90 desalination cycles) and the $\mathrm{pH}$ and ionic concentrations are measured (composition is reported in Tables S3 and S4 in the Supporting Information). Tables S3 and S4 show that during tap water desalination, the $\mathrm{HCO}_{3}{ }^{-}$ion is the dominantly adsorbed anion, while $\mathrm{Na}^{+}$is the dominantly adsorbed cation. Since the $\mathrm{HCO}_{3}{ }^{-}$ion is an amphoteric ion (i.e., an ion which can act as both acid and base), which is in local chemical equilibrium with dissolved $\mathrm{CO}_{2}$, any change in the concentration can result in a local shift of acid-base equilibria, which can affect the $\mathrm{pH}$. This finding further supports the argument that for tap water desalination, $\mathrm{pH}$ changes are mainly due to the adsorption and desorption of $\mathrm{HCO}_{3}{ }^{-}$ions during operation.

In Figure 4, we compare the experimentally measured relative effluent $\mathrm{pH}$ change for tap water desalination during adsorption and desorption with calculated $\mathrm{pH}$ values using Visual MINTEQ 3.1. The calculated $\mathrm{pH}$ follows a similar trend as the measured $\mathrm{pH}$, i.e., the effluent $\mathrm{pH}$ decreases during adsorption and increases during desorption. The calculated values are based on the experimentally determined ionic composition of the water collected during adsorption and desorption, and MINTEQ adjusted the concentration of DIC to maintain the charge and mass balance. Though there is a difference between measured $\mathrm{pH}$ and calculated $\mathrm{pH}$ under different water recovery conditions, the direction of $\mathrm{pH}$ changes is in agreement. This shows that the $\mathrm{pH}$ changes observed during tap water desalination are due to a change in the concentration of DIC (mainly $\mathrm{HCO}_{3}{ }^{-}$ions, considering the $\mathrm{pH}$ and composition of the analyzed water) during adsorption and desorption. The preferential adsorption of $\mathrm{HCO}_{3}{ }^{-}$ions during tap water desalination could mainly be due their high concentration over other anions present in the tap water.

In order to obtain more insights into the effect of DIC on the effluent $\mathrm{pH}$, we have performed an analysis where we changed the concentration reduction of $\mathrm{HCO}_{3}^{-}\left(\Delta c_{\mathrm{HCO}_{3}}{ }^{-}\right)$ during the desalination step, see Figure 5a. For this analysis, we used the ionic composition of the water during adsorption and desorption of the $50 \%$ water recovery experiment (Supporting Information, Table S3). In order to maintain the charge balance, we adjusted the concentration of $\mathrm{Na}^{+}$ions accordingly. Figure 5a shows that the $\mathrm{pH}$ changes are dependent on $\Delta c_{\mathrm{HCO}_{3}}{ }^{-}$and that an increased removal of
$\mathrm{HCO}_{3}{ }^{-}$ions during the adsorption step results in more pronounced $\mathrm{pH}$ changes.

Next, we predicted the scaling potential as a function of water recovery. To do this, we calculated the $\mathrm{pH}$ of the water collected during desorption using Visual MINTEQ software for the $50 \%$ water recovery experiment based on the measured ionic composition. To calculate the $\mathrm{pH}$ of the effluent water during desorption at higher water recoveries, the ionic composition of the solution was calculated by decreasing the volume during desorption while maintaining the total amount of ions desorbed during discharge. Using these calculated ionic compositions, the $\mathrm{pH}$ of water during desorption is predicted using MINTEQ as well as the Langelier Saturation Index (LSI). The LSI is a measure to express the scaling potential based on $\mathrm{pH}$, total dissolved solids (TDS), alkalinity, and the concentration of $\mathrm{Ca}^{2+}$ ions. Figure $5 \mathrm{~b}$ shows that for water recoveries higher than $70 \%$, we observe a significant scaling potential (LSI > 0.5), and the scaling potential increases with water recovery.

As shown in Figure 5a, during tap water desalination, $\mathrm{pH}$ changes are mainly caused by the adsorption and desorption of carbonate species. If carbonate species are not present, however, $\mathrm{pH}$ changes are attributed to the effect of the difference in mobilities of $\mathrm{Na}^{+}, \mathrm{Cl}^{-}, \mathrm{H}^{+}$, and $\mathrm{OH}^{-}$ions on individual ion transport rates. These two different phenomena result in the inversion of the direction of $\mathrm{pH}$ changes experimentally observed (Figure $3 \mathrm{a}, \mathrm{b}$ ). To obtain more insights, we have calculated the average effluent $\mathrm{pH}$ change for a $20 \mathrm{mM} \mathrm{NaCl}$ solution based on the theory as previously described and also for an artificial water solution with a total concentration of salts equal to $20 \mathrm{mM}$, with equimolar concentrations of $\mathrm{NaCl}$ and $\mathrm{NaHCO}_{3}$, using Visual MINTEQ 3.1. Figure $6 \mathrm{a}$ shows the calculated $\mathrm{pH}$ changes for a $\mathrm{NaCl}$ solution as a function of the concentration reduction of $\mathrm{NaCl}$ during desalination, $\Delta c_{\mathrm{Cl}^{-}}$, whereas in Figure $6 \mathrm{~b}$, we show $\mathrm{pH}$ changes for the case of overall $\Delta c=3.45 \mathrm{mM}$, but here the ratio between the adsorption of $\mathrm{Cl}^{-}$and $\mathrm{HCO}_{3}{ }^{-} / \mathrm{CO}_{3}{ }^{2-}$ is varied. Figure 6 clearly shows that the direction of the average $\mathrm{pH}$ changes during adsorption and regeneration is exactly opposite for these two cases. Increasing $\Delta c_{\mathrm{Cl}^{-}}$results in more notable $\mathrm{pH}$ changes, with an average $\mathrm{pH}$ above the feed water $\mathrm{pH}$ during the adsorption step and below during the desorption step. In the case of artificial tap water, $\mathrm{pH}$ changes become more notable with the increasing adsorption of 
carbonate species $\left(\mathrm{HCO}_{3}{ }^{-}\right.$and $\left.\mathrm{CO}_{3}{ }^{2-}\right)$, resulting in a $\mathrm{pH}$ decrease during adsorption and increase during desorption. This result highlights the importance to study $\mathrm{pH}$ changes under practical desalination conditions and the need to control effluent $\mathrm{pH}$ changes by reducing $\mathrm{HCO}_{3}{ }^{-}$adsorption, in order to mitigate scaling problems.

In conclusion, we studied $\mathrm{pH}$ changes in MCDI and i-MCDI using aged electrodes, with a $\mathrm{NaCl}$ solution and with tap water. When dynamic steady state is reached, the observed effluent $\mathrm{pH}$ does not significantly change during desalination. The trend of these $\mathrm{pH}$ changes with a $\mathrm{NaCl}$ feed water purged with $\mathrm{N}_{2}$ is in agreement with our theory that only considers the differences in diffusion coefficients of the ions, which indicates that non-Faradaic processes are the main cause of $\mathrm{pH}$ changes with aged electrodes in MCDI. This finding is significantly different from the existing understanding that Faradaic processes are the major cause of $\mathrm{pH}$ changes in MCDI. In addition, we showed that $\mathrm{pH}$ changes observed for tap water desalination show different dynamics than for $\mathrm{NaCl}$ : the effluent $\mathrm{pH}$ increases during desorption. We explain this inversion of the direction by the adsorption of bicarbonate ions $\left(\mathrm{HCO}_{3}{ }^{-}\right)$during desalination and by the desorption during regeneration. This work also shows that in future studies on $\mathrm{pH}$ changes in CDI, experiments with aged electrodes are strongly recommended.

\section{ASSOCIATED CONTENT}

\section{SI Supporting Information}

The Supporting Information is available free of charge at https://pubs.acs.org/doi/10.1021/acs.est.1c04479.

Additional information about $\mathrm{pH}$ calculations, water compositions, diffusion coefficients used for theoretical calculations, charge efficiency, concentration reduction, $\mathrm{pH}$ profiles during aging, and LSI calculation procedure (PDF)

\section{AUTHOR INFORMATION}

\section{Corresponding Authors}

Jouke E. Dykstra - Environmental Technology, Wageningen University, 6708 WG Wageningen, The Netherlands;

(1) orcid.org/0000-0002-0377-4779;

Email: jouke.dykstra@wur.nl

Slawomir Porada - Wetsus, European Centre of Excellence for Sustainable Water Technology, 8911 MA Leeuwarden, The

Netherlands; Email: slawomir.porada@wetsus.nl

\section{Authors}

Antony C. Arulrajan - Environmental Technology, Wageningen University, 6708 WG Wageningen, The Netherlands; Wetsus, European Centre of Excellence for Sustainable Water Technology, 8911 MA Leeuwarden, The Netherlands; 10 orcid.org/0000-0001-9306-449X

Albert van der Wal - Environmental Technology, Wageningen University, 6708 WG Wageningen, The Netherlands

Complete contact information is available at: https://pubs.acs.org/10.1021/acs.est.1c04479

\section{Author Contributions}

The manuscript was written through contributions of all authors. All authors have given approval to the final version of the manuscript.

\section{Notes}

The authors declare no competing financial interest.

\section{ACKNOWLEDGMENTS}

This work was performed in the cooperation framework of Wetsus, European Centre of Excellence for Sustainable Water Technology (www.wetsus.nl). Wetsus is cofunded by the Dutch Ministry of Economic Affairs and Ministry of Infrastructure and Environment, the European Union Regional Development Fund, the Province of Fryslân, and the Northern Netherlands Provinces. This work is part of a project that has received funding from the European Union's Horizon 2020 research and innovation programme under the Marie Skłodowska-Curie grant agreement No 665874. The authors thank the participants of the research theme "Concentrates" for fruitful discussions and financial support.

\section{REFERENCES}

(1) Kharraz, J. E.; El-Sadek, A.; Ghaffour, N.; Mino, E. Water Scarcity and Drought in WANA Countries. Procedia Eng. 2012, 33, 14-29.

(2) Gude, V. G. Desalination and sustainability - An appraisal and current perspective. Water Res. 2016, 89, 87-106.

(3) Suss, M. E.; Porada, S.; Sun, X.; Biesheuvel, P. M.; Yoon, J.; Presser, V. Water Desalination via Capacitive Deionization: What Is It and What Can We Expect from It? Energy Environ. Sci. 2015, 8, 2296-2319.

(4) Porada, S.; Zhao, R.; van der Wal, A.; Presser, V.; Biesheuvel, P. M. Review on the Science and Technology of Water Desalination by Capacitive Deionization. Prog. Mater. Sci. 2013, 58, 1388-1442.

(5) Uwayid, R.; Seraphim, N. M.; Guyes, E. N.; Eisenberg, D.; Suss, M. E. Characterizing and Mitigating the Degradation of Oxidized Cathodes during Capacitive Deionization Cycling. Carbon 2021, 173, $1105-1114$.

(6) He, D.; Wong, C. E.; Tang, W.; Kovalsky, P.; Waite, T. D. Faradaic Reactions in Water Desalination by Batch-Mode Capacitive Deionization. Environ. Sci. Technol. Lett. 2016, 3, 222-226.

(7) Lado, J. J.; Pérez-Roa, R. E.; Wouters, J. J.; Isabel TejedorTejedor, M.; Anderson, M. A. Evaluation of Operational Parameters for a Capacitive Deionization Reactor Employing Asymmetric Electrodes. Sep. Purif. Technol. 2014, 133, 236-245.

(8) Chen, T.; Neville, A.; Yuan, M. Calcium carbonate scale formation-assessing the initial stages of precipitation and deposition. J. Pet. Sci. Eng. 2005, 46, 185-194.

(9) Gabrielli, C.; Maurin, G.; Poindessous, G.; Rosset, R. Nucleation and Growth of Calcium Carbonate by an Electrochemical Scaling Process. J. Cryst. Growth 1999, 200, 236-250.

(10) Wang, T.; Zhang, C.; Bai, L.; Xie, B.; Gan, Z.; Xing, J.; Li, G.; Liang, H. Scaling Behavior of Iron in Capacitive Deionization (CDI) System. Water Res. 2020, 171, 115370.

(11) Dykstra, J. E.; Keesman, K. J.; Biesheuvel, P. M.; van der Wal, A. Theory of $\mathrm{PH}$ Changes in Water Desalination by Capacitive Deionization. Water Res. 2017, 119, 178-186.

(12) Lee, J.-H.; Bae, W.-S.; Choi, J.-H. Electrode Reactions and Adsorption/Desorption Performance Related to the Applied Potential in a Capacitive Deionization Process. Desalination 2010, 258, 159163.

(13) Landon, J.; Gao, X.; Omosebi, A.; Liu, K. Emerging Investigator Series: Local PH Effects on Carbon Oxidation in Capacitive Deionization Architectures. Environ. Sci.: Water Res. Technol. 2021, 7, 861-869.

(14) Biesheuvel, P. M.; Hamelers, H. V. M.; Suss, M. E. Theory of Water Desalination by Porous Electrodes with Immobile Chemical Charge. Colloids Interfac. Sci. Commun. 2015, 9, 1-5.

(15) Zhang, C.; He, D.; Ma, J.; Tang, W.; Waite, T. D. Faradaic Reactions in Capacitive Deionization (CDI) - Problems and Possibilities: A Review. Water Res. 2018, 128, 314-330. 
(16) Zhao, R.; Satpradit, O.; Rijnaarts, H. H. M.; Biesheuvel, P. M.; van der Wal, A. Optimization of Salt Adsorption Rate in Membrane Capacitive Deionization. Water Res. 2013, 47, 1941-1952.

(17) Cohen, I.; Avraham, E.; Bouhadana, Y.; Soffer, A.; Aurbach, D. The Effect of the Flow-Regime, Reversal of Polarization, and Oxygen on the Long Term Stability in Capacitive de-Ionization Processes. Electrochim. Acta 2015, 153, 106-114.

(18) Cohen, I.; Avraham, E.; Bouhadana, Y.; Soffer, A.; Aurbach, D. Long Term Stability of Capacitive De-Ionization Processes for Water Desalination: The Challenge of Positive Electrodes Corrosion. Electrochim. Acta 2013, 106, 91-100.

(19) Gao, X.; Omosebi, A.; Landon, J.; Liu, K. Surface charge enhanced carbon electrodes for stable and efficient capacitive deionization using inverted adsorption-desorption behavior. Energy Environ. Sci. 2015, 8, 897-909.

(20) Gao, X.; Omosebi, A.; Landon, J.; Liu, K. Enhanced Salt Removal in an Inverted Capacitive Deionization Cell Using Amine Modified Microporous Carbon Cathodes. Environ. Sci. Technol. 2015, 49, 10920-10926.

(21) Gao, X.; Omosebi, A.; Holubowitch, N.; Liu, A.; Ruh, K.; Landon, J.; Liu, K. Polymer-Coated Composite Anodes for Efficient and Stable Capacitive Deionization. Desalination 2016, 399, 16-20.

(22) Biesheuvel, P. M.; Zhao, R.; Porada, S.; van der Wal, A. Theory of Membrane Capacitive Deionization Including the Effect of the Electrode Pore Space. J. Colloid Interface Sci. 2011, 360, 239-248.

(23) Choi, J.-H.; Yoon, D.-J. The Maximum Allowable Charge for Operating Membrane Capacitive Deionization without Electrode Reactions. Sep. Purif. Technol. 2019, 215, 125-133.

(24) Srimuk, P.; Ries, L.; Zeiger, M.; Fleischmann, S.; Jäckel, N.; Tolosa, A.; Krüner, B.; Aslan, M.; Presser, V. High Performance Stability of Titania Decorated Carbon for Desalination with Capacitive Deionization in Oxygenated Water. RSC Adv. 2016, 6, 106081-106089.

(25) Srimuk, P.; Zeiger, M.; Jäckel, N.; Tolosa, A.; Krüner, B.; Fleischmann, S.; Grobelsek, I.; Aslan, M.; Shvartsev, B.; Suss, M. E.; Presser, V. Enhanced Performance Stability of Carbon/Titania Hybrid Electrodes during Capacitive Deionization of Oxygen Saturated Saline Water. Electrochim. Acta 2017, 224, 314-328.

(26) Tang, W.; He, D.; Zhang, C.; Kovalsky, P.; Waite, T. D. Comparison of Faradaic Reactions in Capacitive Deionization (CDI) and Membrane Capacitive Deionization (MCDI) Water Treatment Processes. Water Res. 2017, 120, 229-237.

(27) Ogumi, Z.; Takehara, Z.; Yoshizawa, S. Gas Permeation in SPE Method: I . Oxygen Permeation Through Nafion and NEOSEPTA. J. Electrochem. Soc. 1984, 131, 769.

(28) Dykstra, J. E. Desalination with porous electrodes : Mechanisms of ion transport and adsorption. Ph.D. Thesis, Wageningen University, 2018.

(29) van Limpt, B.; van der Wal, A. Water and Chemical Savings in Cooling Towers by Using Membrane Capacitive Deionization. Desalination 2014, 342, 148-155.

(30) Fritz, P. A.; Boom, R. M.; Schroen, K. Polyelectrolyte-Activated Carbon Composite Electrodes for Inverted Membrane Capacitive Deionization (IMCDI). Sep. Purif. Technol. 2019, 220, 145-151. 